\title{
Engaging Civil Society Organizations in Adolescent Reproductive Health Policy Process in Mainland of China
}

\author{
Xu Jieshuang ${ }^{1}$, Verhart Noortje ${ }^{2}$, Stephen Pearson ${ }^{3}$, Qian $\mathrm{Xu}^{1 *}$ \\ ${ }^{1}$ School of Public Health, Fudan University, Key Laboratory of Public Health Safety, Ministry of Education, \\ Shanghai, China \\ ${ }^{2}$ Royal Tropical Institute, Amsterdam, The Netherlands \\ ${ }^{3}$ The Nuffield Centre for International Health \& Development, Leeds Institute of Health Sciences, \\ University of Leeds, Leeds, UK \\ Email: *xqian@fudan.edu.cn
}

Received April $7^{\text {th }}, 2013$; revised May 16 ${ }^{\text {th }}, 2013$; accepted May 29 ${ }^{\text {th }}, 2013$

\begin{abstract}
Copyright (C) $2013 \mathrm{Xu}$ Jieshuang et al. This is an open access article distributed under the Creative Commons Attribution License, which permits unrestricted use, distribution, and reproduction in any medium, provided the original work is properly cited.
\end{abstract}

\begin{abstract}
This paper explored how Chinese civil society organizations (CSOs) had been involved in an adolescent reproductive health policy process and its implications for other developing countries with similar political and social contexts. The case study was the $6^{\text {th }}$ cycle of the Country Program on adolescent reproductive health (Jan. 2006-Dec. 2010). It was a multi-phased, retrospective qualitative study in Guangxi autonomous region. Six categories of policy actors including politician, CSO, policy-maker, health manager, development partner and researcher were interviewed, 34 documents were reviewed and 1 participatory stakeholder workshop was held between Jun. 2007 and Apr. 2008. We focused on different CSOs that had been involved in different stages of the policy process, what strategies they had used to interact with the policy process and how they influenced the content and implementation of the policy. Our results showed that new forms of CSOs in China were emerging, with different mechanisms being used to express their voice and influence the policy process. The involvements of CSOs in the adolescent reproductive health policy process also showed how new opportunities were arising in a rapidly changing Chinese political context, but various factors might affect their involvement in policy process. Critical amongst these were the characteristics of the CSOs, the wider political context of the country and the nature of the policy itself.
\end{abstract}

Keywords: Health Policy; Adolescent Reproductive Health; Civil Society

\section{Introduction}

China has the largest population of adolescents in the world: nearly 194 million adolescents aged 10 - 19 account for $14.6 \%$ of the national population (Zhongguo guojia tongjiju 中国国家 统计局, 2009). Because of long-lasting cultural traditions in China, sex has been viewed as a taboo subject with concerns that promoting sexuality education for adolescents encourages sexual behaviors (Wang et al., 2005). It is very hard for students to get systematic and comprehensive sexual and reproductive information from their schools (Zhang et al., 2007). China's social and economic development and improvements in its people's lives and health standards have been accompanied by a continuing decrease in the age of sexual maturity (Zhongguo xuesheng tizhi yu jiankang yanjiuzu 中国学生体质与健 康研究组, 2002). Changing social values and norms related to sex and marriage have affected adolescents' attitudes and behaviors (Gao et al., 2003). These changes can be measured by increases in premarital sexual behaviors and problems (such as unintended conceptions, sexually transmitted infections, and even HIV/AIDS) associated with adolescents' lack of sexual and reproductive health knowledge and skills (Gao et al., 2003).

\footnotetext{
*Corresponding author.
}

The 1994 International Conference on Population and Development (ICPD) resulted in a Program of Action agreed by 179 countries (including China). Adolescent and reproductive health issues and the need for appropriate services and counseling specifically suited for that age group were important aspects of the Program. In response to the new prominence given to reproductive health in international fora, the Chinese government gave more emphasis in policies to high-quality reproductive health/family planning information and services (Guojia renkou yu jihua shengyu weiyuanhui 国家人口与计划 生育委员会, 2000). This represented a shift from the government's previous focus on prioritizing population control.

The ICPD also called for greater participation of civil society in reproductive health matters to improve policy formulation and implementation. Civil society organizations (CSOs) have been identified as one of the most important determinants affecting policy processes (HEPVIC Consortium, 2007).

China had a highly centralized political system, which was based on a planned economy and administrative management (Wang, 2010). The development of CSOs in China had been strict and therefore limited under those circumstances especially before the 1980s. Since the early 1990s, however, reforms had brought changes to the political system and public 
management, which had created a more favorable environment for CSOs and citizen participation (Lu, 2005). Since then, the Chinese government had actively called on these so-called "social forces" to subsidize and filled gaps in state services (Wang, 2009). The number and variety of CSOs have grown, alongside their roles, capacities and scope of activities. In relation to the need for better adolescent reproductive health (ARH) services and the ICPD meeting calling for increasing inclusion of CSOs, including in the area of reproductive health for adolescents, CSOs are able to gain space to influence the policy process in China.

In this article, a United Nations Population Fund (UNFPA) sponsored national ARH program was used as a policy case study. The article explored how Chinese CSOs had been involved in this particular policy process, focusing on the formulation of this program action plan at the national level and the implementation at county level. We also analyzed the strategies that CSOs used to influence the program, what impact that had on the content and the implementation of the program and the factors that influenced their strategies and impact.

\section{Methods}

The study was approved by the institutional review board of the School of Public Health, Fudan University, Shanghai, China (Identification code 07-01-0067).

\section{Study Design}

Data for this article were collected in the HEPVIC (Health Policy Making in Vietnam, India and China) project aiming to understand and compare how health policies were made in three Asian countries. A full description of the methods used was reported by Green et al. (2011). The study in China was conducted in Guangxi autonomous region, with a focus on an ARH policy process developed at the national level and implemented in one project county. As a summary, this was a multiphased, retrospective qualitative study structured around three phases:

- Phase one-preliminary data collection and data analysis

- Phase two-main data collection

- Phase three-main data analysis and follow-up

This incremental approach to the research design allowed phases two and three to be informed by the results of the previous phases. Non-random, purposive sampling was used to select respondents.

\section{Participants}

To ensure that the voices of different types of actors were heard in the research, six categories of policy actors were developed (see Table 1), with respondents recruited for each category. At Phase One, 2 key informants with knowledge, experience and perceptions of the case study policy processes were selected. One was an ARH expert who has been involved in policy development processes; another was a researcher whose research field had been focusing on ARH in China for many years. At Phase Two, 13 respondents were key actors identified by the Phase One respondents and research team who had been involved in policy making or implementation process, and through snowballing by phase two respondents until information saturation.

Documents review provided data on the evidence and written documents informing the policy process. They also provided another data source to be compared with other sources to identify and explain consistencies and inconsistencies in reporting. 34 documents were selected which provided a written record of some aspect of the case study's policy processes. They included 7 policy documents at the national and local level, 9 webpage from the websites of UNFPA, China Family Planning Association (CFPA) 中国计划生育协会, China Youth Network (CYN) 中国青年网络 and National Population and Family Planning Commission (NPFPC) 国家人口与计划生育委员会, 7 research report of CP6 ARH program, 6 meeting minutes and 5 other documents. Finally, follow-up interviews were done through phone calls, emails and participatory stakeholder workshop, which was held involving policy process actors and other stakeholders to raise, justify and re-examine different views (see Table 2).

\section{Procedure}

Semi-structured in-depth interviews were conducted in Chinese face-to-face between Jun. 2007 and Apr. 2008. After obtaining an informed consent form, a digital voice recorder was used to record all interviews. All interviews were conducted in a private room. The author acted as interviewer, and another researcher acted as observer. The observer kept track of the questions asked, recorded any important emergent issues the interviewer needed to ask as follow-up, and noted any important non-verbal interactions. All interviews were transcribed into Chinese by the research observer soon after completion. Transcripts were checked to "clean" the data, and to allow the

Table 1.

Summary of interviewees recruited.

\begin{tabular}{|c|c|c|}
\hline Type of respondent & Definition & $\begin{array}{l}\text { Number of } \\
\text { respondent }\end{array}$ \\
\hline Politician & Political figures at all levels (country, province, state), but probably not directly involved in health policy processes & 1 \\
\hline Civil society & $\begin{array}{l}\text { Organised entities, including private sector NGOs, patients’ organisations, Women's Committees, professional } \\
\text { associations, etc. }\end{array}$ & 4 \\
\hline Policy-maker & $\begin{array}{l}\text { Health public sector officials whose responsibilities include the formulation, development, monitoring and } \\
\text { implementation of health policies }\end{array}$ & 3 \\
\hline Health manager & $\begin{array}{l}\text { Programme managers and health staff (public and private sectors) at the frontline of service delivery who focus on } \\
\text { policy implementation }\end{array}$ & 4 \\
\hline Development partner & $\begin{array}{l}\text { All international funding bodies that may or may not be physically represented in the country, but may affect health } \\
\text { policy processes }\end{array}$ & 1 \\
\hline Academic/researcher & Academic scholars (individuals or organisations) who possess knowledge pertinent to the policy processes & 2 \\
\hline
\end{tabular}


XU J. S. ET AL.

Table 2.

Summary of data collection.

\begin{tabular}{|c|c|c|c|}
\hline \multirow{2}{*}{ Method } & \multicolumn{3}{|c|}{ Phase } \\
\hline & One & Two & Three \\
\hline In-depth interview & $\begin{array}{l}1 \text { ARH expert } \\
1 \text { academic } \\
(\mathrm{n}=2)\end{array}$ & $\begin{array}{l}1 \text { politician } \\
4 \text { CSO members } \\
3 \text { policy-makers } \\
4 \text { health managers } \\
1 \text { development partner } \\
(\mathrm{n}=13)\end{array}$ & \\
\hline Document review & & $\begin{array}{l}7 \text { policy documents } \\
9 \text { from websites } \\
7 \text { research reports } \\
6 \text { meeting minutes } \\
5 \text { other documents } \\
(\mathrm{n}=34)\end{array}$ & \\
\hline
\end{tabular}

12 participants were presented at Nanning, Guangxi in Feb $14^{\text {th }}, 2008$.

Participatory stakeholder workshop $(\mathrm{n}=1)$

interviewer and observer to confirm the accuracy of transcription. Personal names and other identifier information were removed from the transcripts. Access to data (transcripts, records) was restricted to approved members of the research team. Data were stored in secure electronic locations (access-protected directories on computers).

Once a relevant document was identified, a full-text paper or electronic copy was obtained. As documents were of different lengths, layouts and formats, a pro forma sheet was therefore designed to extract pertinent information and register interpretations in a standardized format. One pro forma sheet was completed for each document. It was divided into four sections: basic information, content, context, and any other comments.

\section{Data Analysis}

A framework approach was taken to analyze and triangulate the three data sources (Ritchie, 1993), assisted by NVivo 7. NVivo is a qualitative data analysis computer software package. It has been designed for qualitative researchers working with very rich text-based and/or multimedia information, where deep levels of analysis on small or large volumes of data are required.

The thematic framework was determined by considering and synthesizing two key factors: the key concepts and themes identified in the project conceptual framework and the themes emerging from familiarization with the data. Each transcript and document was coded both by the author and research observer. Different opinions were then discussed until consistency was reached.

\section{Findings}

\section{CSOs that Have Been Involved in Policy Process}

The policy case study was embodied by a national program called the Country Program 6 (CP6) ARH (Country Program $6^{\text {th }}$ cycle Adolescent Reproductive Health-see Figure 1) and sponsored by UNFPA. UNFPA had assisted the Chinese government to implement 5 cycles of reproductive health/family planning country programs (CP1-CP5) by the end of 2005. CP4 and CP5 started to have ARH program components and these programs were implemented by the CFPA in 30 program counties in 1998 (see Figure 1). The country programs were led by
UNFPA in collaboration with the Chinese government. Four main types of CSOs were involved in the policy process around the CP6 ARH program:

UNFPA is the world's largest international funder of population cooperation activities. Its two main roles in the CP6 ARH program were as the donor and partner for implementation with the Chinese government. This respondent recalled the pivotal role UNFPA had in initiating, facilitating and coordinating all stakeholder collaboration in the formulation and implementation of the program:

"UNFPA and the Chinese government both provided 50\% of the program fund ... Apart from funding the program, UNFPA played the role of promotion and acceleration. First it pushed our government, and then coordinated between the other actors (CSO member 2)".

CFPA, formed in 1980, is a national non-profit organization, technically directed by the NPFPC. It has a close relationship with the government, which funds its running costs. Its network covers most parts of China and reaches the grass-roots, with an effective operation system and regular activities.

CYN was formed in 2004 by a group of university students in Beijing, supported by UNFPA and CFPA. It was a volunteer based national youth organization. Its sub-national network had youth representatives at the program county level. This respondent described the rather small nature of this CSO which is relatively independent from government:

"6 - 7 university students called a core group at national level and 30 youth representatives at county level (one per county). Together they raised funds from UNFPA, Ford Foundation and other international resources (CSO member 1)."

Expert panels from the Ministry of Health (MOH) and NPFPC mainly included researchers from domestic research institutions, universities, and civil society organizations. Experts in the panels were selected by the MOH or NPFPC based on their expertise and profile in ARH and other relevant policy areas. They worked as a government "think tank" to provide policy suggestions to policy makers.

\section{CSOs' Involvement in Different Stages of the Policy Process}

The policy process could roughly be divided in four stages 
XU J. S. ET AL.

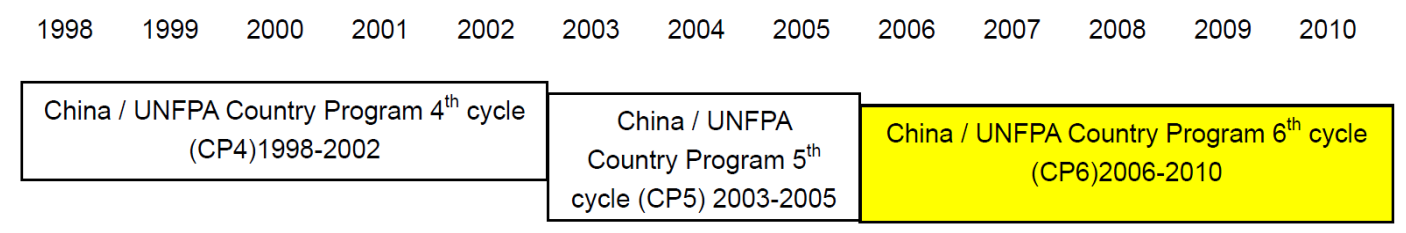

PATH Adolescent Reproductive Health Program

2001-2005

Figure 1.

ARH program in China.

(Sutcliffe, 2006): agenda setting, formulation, implementation and monitoring \& evaluation. It was through these stages that the role and influence of CSOs was being looked at in this study.

\section{Agenda Setting}

Since the 1980s, the Chinese government has started to encourage school health education. This gradually became focused on sexual \& reproductive health and prevention of HIV/AIDS. This development followed the Chinese commitments and the action plan that was developed after ICPD. As one respondent recalled:

"Reproductive health/family planning work in China [came to] meet international trends [...] Adolescent sexual and reproductive health had thus increasingly become a work-emphasis of the Chinese government now (policy maker 1)".

Concurrently, UNFPA commissioned an evaluation of its ARH component at the end of the UNFPA Country Program 5. The evaluation identified some successful experiences that had improved adolescent reproductive health (Hu et al., 2005). On the basis of these results, UNFPA decided to extend their support for ARH in CP6. The newly funded CP6 ARH program was timely, as it coincided with the government's ICPD commitments and also their new political focus on a human development and service-orientated approach to the family planning system. A policy maker recalled:

"The intervention fields of this [CP6 ARH] program were both [ones] that UNFPA and the Chinese government paid attention to, being identical with the government's work emphasis (policy maker 2)”.

As a result UNFPA, in collaboration with the Chinese government, organized a first consultative meeting in Beijing in November, 2005 to discuss the upcoming CP6 program. Present at this meeting were the MOH, NPFPC, and their expert panels. The increasing commitment of the Chinese government to meet international standards and the success of CP5 ensured that ARH had enhanced and sufficient visibility on the political (and therefore, policy-making) agenda.

\section{Policy Formulation}

With ARH better-established on the political agenda, activities shifted towards formulating the ARH policy. In December, 2005, UNFPA organized a second national consultative conference in Beijing, where many stakeholders were present.

"UNFPA invited all actors who had been involved in the CP5 ARH program-including Marie Stopes International, the $M O H$ and its expert panel, the NPFPC and its expert panel, CFPA and CYN to have a discussion about the China/UNFPA CP6 Action Plan 2006-2010 (development partner)”.
Actors who had been involved in implementation of the CP5 ARH program presented their own proposals for the policy. For example, this respondent recalled the inputs provided by the relatively newer-established and less powerful actor, the CYN:

"CYN core group members presented proposal on youth participation and the CFPA presented its proposal on life skillsbased education at the meeting, and led the discussion respectively (CSO member 2)".

Recognizing that the CYN had relatively less capacity and experience as an actor in policy formulation, UNFPA and CFPA actively supported CYN's participation in the conference:

"UNFPA management staff supported youth participation in the ARH program. They and CFPA helped CYN to design its proposal, and UNFPA persuaded the MOH and the NPFPC to accept it at that conference... (CSO member 1)".

A policy maker confirmed the role of the CFPA in the following statement:

"During the whole development process of the CP6 Country Program Action Plan, the CFPA, as a CSO, played a key role. It was very active in China, and especially experienced in the ARH field. Why the NPFPC paid attention to the ARH issue was due to this fact. The CFPA, as an NGO, could actively involve itself in cooperative programs. Where their work [in 4th and 5th cycle ARH program] is effective, they can push forward the country's policy development (Policy maker 1)."

After two days discussion, the "China/UNFPA CP6 Action Plan 2006-2010” was drafted. UNFPA then presented the draft plan to the Ministry of Commerce (the leading agency of the Chinese government dealing with foreign affairs), which circulated the Plan within Chinese government departments. The final decision-making for the "China/UNFPA CP6 Action Plan 2006-2010" was undertaken by the Ministry of Commerce, the $\mathrm{MOH} /$ expert panel, the NPFPC/expert panel, and UNFPA in March, 2006.

\section{Program Implementation}

Once approved, a National Coordination Committee was set up for program administration. Membership included UNFPA, Ministry of Commerce, MOH, NPFPC and Marie Stopes International. Through regular National Coordination Committee meetings organized by UNFPA, an active partnership approach was promoted at the national level.

The CP6 ARH program was implemented in 30 counties (including one project county in Guangxi, in which data were collected for this research). The CP6 ARH Program prioritized high-quality ARH information and services, reflecting the ICPD-led focus on these areas. The CFPA had accumulated successful experiences in previous cycles of the ARH program 
in providing life-skilled peer education. They focused on peer education and social mobilization using their grass-roots network, while CYN mainly focused on youth participation.

Similar to the policy formulation stage, UNFPA supported the participation of CYN in the implementation of the program from the start. This had major consequences:

“At the NPFPC's CP6 program launch meeting in April 2006 in Beijing, UNFPA helped CYN gain a two-hour slot to address young people's abilities. CYN had a session entitled 'Why Should Adults Cooperate with Youths?'...I felt that the session had the greatest influence on the NPFPC. As a result [of it], the MOH invited CYN to deliver the same session at their CP6 program launch meeting [...] Later the NPFPC would call upon CYN to do many things - the situation really changed after that session (CSO member 1)."

At county level, a county leadership group was established by local government to ensure good multi-departmental coordination and collaboration of the program. All relevant departments in local government were involved in this group including the CFPA county branch local youth representatives (the CYN's sub-national network). This respondent remembered the supervisory support provided to the youth representative by another member from the county leadership group.

"UNFPA hope that youth could be involved in the county leadership group and dialogue would happen between youth and adults. That's was why a supervisor from this group was set up to ensure youth's voice could be heard at local level (development partner)."

Similar to support provided in the policy formulation stage, this arrangement aimed to help youth representatives become actively involved in local decision making processes. However, youth representatives had a limited mandate. In this project county, he/she was only able to introduce ARH advocacy activities for the "floating" (internal migrant) population.

"Progress was not that optimistic. The youth representatives were weak; at the same time, they were not that bold. We noticed this problem when we monitored our program. Young people did take some initiative, sometimes not completely right, but the current policy-making system did not foster this kind of participation. Still, we would like to improve youth participation in the policy process (development partner)."

"The CYN was a kind of non-governmental organization without a certain influence and scale, [and so] was not able to be involved [in policy-making at local level] (health manager 3)”.

\section{Monitoring \& Evaluation}

At the national level, expert panels regularly visited program counties. These visits were commissioned by the $\mathrm{MOH}$ and NPFPC. The resulting reports informed and helped identity important gaps in the further implementation of the policy. This respondent recalled how the visits prioritized capacity strengthening for successful program implementation:

"In our schedule, expert panel members were required to supervise program counties twice per year and write reports after each field visit. The role of supervision was to help program counties to improve capabilities of implementation and provide technical support (policy maker 1 )”.

\section{Different Strategies CSOs Used to Influence the Policy Process}

The analysis identified four main strategies used by CSOs to influence the policy process.

\section{Building a Reputation as a Trustworthy and Successful Policy Actor}

UNFPA had been considered as a reliable partner, due to the successful results of the country programs on ARH. At the same time, UNFPA had been eager to continue their country programs because of their global mandate to improve the sexual health among adolescents worldwide. Together with the positive outcomes of the evaluation of CP5, UNFPA had been able to continue their work. This had given them leverage to influence the policy process and to ensure that several actors were involved at different stages.

The CFPA had been involved in the ARH program as an active actor since 1998. Their successful experiences were cited by these respondents as having helped CSOs to strengthen their reputation and gain support from government leaders and departments:

"About 10 years ago, some non-government organization like CFPA started to collaborate with international organizations focusing on ARH issues. CFPA had accumulated successful experiences and summarized good models [of ARH education and services] (policy maker 2)".

"I think CFPA was very active in China in terms of piloting programs in the ARH field. Why NPFPC paid attention to the ARH issue had something to do with CFPA's successful work [in previous ARH programs] (policy maker 1 )”.

\section{Being Involved in Expert Panels}

Expert panels have been a well-used mechanism in the policy making process in China (in some cases, even policy-drafting groups). When expert panels were asked to provide evidence through research and to form advisory committees, their voice were listened to by policy makers due to long-established and trusting working relationships.

"We were not health professionals, we can only made use of expert panel [in policy making] (policy maker 1)”.

"We didn't have national data reflecting ARH issues [when making the policy]. Relevant information was from research report [provided by expert panel members] focusing on a certain area, but it did give us basic scenario of how serious the problem was (policy maker 2)”.

\section{Lobbying}

Some core group members from CYN had worked as Youth Counselors for the International Planned Parenthood Federation (IPPF) from 2003-2008. This work enabled good working relationships to be established with policy makers and expert panel members from NPFPC. Consequently, the CYN used these good relationships to advocate for acceptance of their proposal on youth participation during breaks and dining periods at the second consultative meeting in Beijing:

“We had many opportunities to participate at IPPF's meetings with policy makers from NPFPC. We took advantage of these opportunities to introduce that CYN was a young people's organization in China, that we had been involved in the ARH program, and how important youth participation was. Over time, you could feel their level of knowledge and understanding of this issue increased (CSO member 2).”

Being Involved as an Implementer of Policy

This strategy was described in a previous section. 


\section{Discussion}

\section{The Involvement and Influence of CSOs in the Policy Process}

The previous sections described the influential involvement of CSOs in the policy process, but how can we explain their involvement and what impact did they actually have on the policy? Gaventa’s (2005) “power cube” approach (see Figure 2) presented a dynamic understanding of how power operates, how different interests could be marginalized from decision making and the strategies needed to increase inclusion. The power cube approach looked at how power was used in three continuums (Gaventa, 2006):

- Places: the levels and places of engagement (local, national, international).

- Spaces: how arenas of power were created (provided or closed, invited and created).

- Power: the degree of visibility of power (visible, hidden and invisible).

The involvement of CSOs in the ARH policy process in China can be analyzed using the above concepts. In terms of spaces, at the national level the consultative conference initiated by UNFPA allowed, besides policy makers, access to CSOs. In addition to UNFPA, policy makers and the expert panels, CFPA and CYN also were invited to discuss the potential policy content. The important roles and successful experiences of the CFPA in previous ARH programs meant they gained credibility and were therefore invited. As described in the results section, CYN "claimed" space through their lobbying strategy and donor support, and were therefore able to pursue their agenda items in the formulation stage of the policy. The expert panels were part of the closed space, as they were trusted and well-established partners of policy makers. However, in addition to the essential role that experts played in the policy process, their inclusion contributed to evidence-based policy making.

The involvement of CSOs could also be understood with reference to the second power cube continuum, power. Experts' power was visible, and based on the policy process procedures in the Chinese context which value the contributions of this group of actors. UNFPA exercised "hidden” power due to their role as the main initiator, developer, funder and implementer of the policy. While the Chinese government was formally in charge of the policy process, without UNFPA the ARH program would not have happened. Also, UNFPA maintained their influence by controlling who got to the decision-making table and what got on the agenda. This enabled CYN to play an important role in the policy process. While they were not able to negotiate their power based on formal rules, they did it based

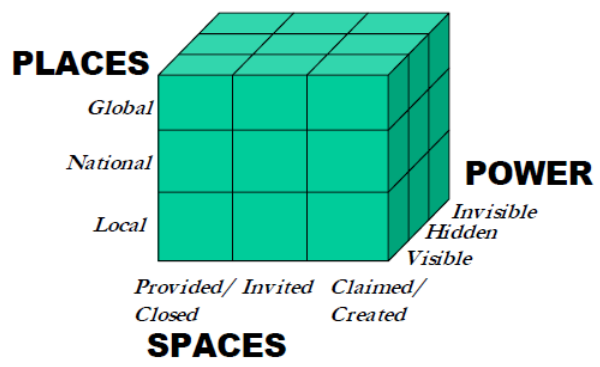

Figure 2.

Power cube theory. on personal contacts and networks. As a result of the CYN lobby, a monitoring indicator was included on the involvement of youth (namely that " $80 \%$ of the program counties should take youth groups' recommendations into consideration when monitoring the program") (The government of China and UNFPA, 2006).

At local level, youth representatives did participate in the program county leadership groups. However, the youth representatives were not able to claim any space. Formally it was an "invited space", but the "invisible" structure of the social and political ideology about policy making renders them unable to conceive of bringing about change in their own interests. The local government kept actual control over the process and made decisions in a "closed" space.

\section{Factors Influencing CSO Engagement in Policy Process}

CSOs' engagement in the policy process could be explained with reference to both contextual factors and the capacity and characteristics of CSOs.

First, this policy case study existed in a specific time period and its social, political and policy-making context. For example, the established mechanism of expert panels in the Chinese policy process (discussed previously) gave them enhanced credibility and legitimacy in this case study. Similarly, the decision to represent the policy issue through a program rather than legislation facilitated the involvement of a more diverse range of actors, as program policy processes were less formal and hierarchical.

The political context helped explain the structure and effectiveness of working relationships between the government and CSOs. CFPA, the largest and the first CSO in China to focus on reproductive health issues, had a close working relationship with the government. Both parties had a similar organizational hierarchy from community up to national level. The CFPA also received their main funding from the government. These two factors made the CFPA an important partner for the Chinese government in the policy process. CSOs in China are generally closely linked to the government, but in that role, they can play an important role in influencing the policy process. Tony Saich (2000) argued for the advantages of this closeness, in that "social organizations could have considerable impact on the policy-making process” by retaining strong linkages to the party and state, far more than if they were to try to create an organization with complete operational autonomy. In another HEPVIC ARH case study in Vietnam, the Youth Union, being "quasi” independent with strong links to government, has also been quite active in national ARH policy process from setting agenda, policy development, to policy implementation (Ha et al., 2010).

Second, CSOs' engagement was associated with their visibility and capacity (technical, financial, social). The prominent visibility and strong capacity of UNFPA in the case study was clear. UNFPA had a long-established and proven working relationship with the Chinese government to successfully implement previous reproductive health programs. Consequently, their influence in the China ARH policy process was extensive.

Though the CFPA and CYN were all classified as CSOs, their characteristics differed. CYN was relatively independent, small-scale, volunteer-based and had limited capacity. Their financial support was mainly program-based and came from international sources. CYN also faced some challenges in terms 
of long-term stability and difficulties to network without a close relationship to the government. The case study showed some evidence of their ability to influence the policy process at the national level due to their personal contacts and donor support. However, at the program county level, there was no clear structure for civil society in decision making. Distrust from local government had marginalized youth representative's input in policy implementation.

\section{Conclusion}

The HEPVIC research project focuses on policy processes within the maternal health field. The findings have shown how policy actors and their relative power is emerging as one of the key determinants in health policy processes, even more than the strength of evidence or other factors that have been studied as potential influencing factors in the policy process (Sutcliffe, 2006). This specific case study on the ARH policy process in China, describes how the different actors involved in different stages of the process, have influenced the content and implementation of the policy. It shows the emergence of new forms of civil society, and different mechanisms through which civil society is able to express their voice and influence the policy process in a rapidly changing Chinese political context.

The role of CSOs and their influence depends on many factors. In this case study, the nature of the policy issue played an important role. Due to international developments such as ICPD, and increasingly visible health problems at the national level, the Chinese government was willing to address ARH issues. At that moment, only a few CSOs had experience in this field, and this was one of the reasons they were invited to contribute to the formulation of the policy. However, being invited to meetings does not mean that organizations have influence on the proceedings or outcomes. In this case, the nature of the policy process, and the important role of UNFPA, enables civil society to make a difference while promoting their own agenda.

The involvement of CSOs in the Chinese policy process shows how new opportunities are arising in a changing political context. While the Chinese tradition of citizen participation has been top-down, this case study shows how civil society is now also playing a proactive role in advising and lobbying. This case study also shows how a process led at the national level may have challenges in being implemented effectively at the local level. This has meant that in the implementation stage, the role of civil society has been less substantial.

Our research was on ARH policy processes in China but, we suggest that some of the findings and implications may be relevant for other developing countries with similar political and social contexts.

\section{Acknowledgements}

HEPVIC was supported by the European Community Sixth Framework Program (INCO-CT-2005-517746). However, the views of the article only reflect those of the authors.

The authors would like to thank colleagues at the School of Public Health, Fudan University and all HEPVIC partners for their contribution during the HEPVIC project. The research that this paper was based on was supported by the EC under FP6. The authors also would like to all the respondents and facilitators in the research field.

\section{REFERENCES}

Zhongguo jihua shengyu xiehui 中国计划生育协会 (2006). Zhongguo jihua shengyu xiehui zhangcheng 中国计划生育协会章程. 2006 nian quanguo huiyuan daibiao dahui tongguo, Beijing. 2006 年 全国会员代表大会通过，北京.

Zhongguo xuesheng tizhi yu jiankang yanjiuzu 中国学生体质与健康 研究组 (2002). 2000 nian zhongguo xuesheng tizhi yu jiankang diaoyan baogao 2000 年中国学生体质与健康调研报告. Beijing: Gaodeng jiaoyu chubanshe. 北京: 高等教育出版社.

Zhongguo qingnian wangluo 中国青年网络 (2007). 2007 nian zhongguo qingnian wangluo nianhui baogao. Beijing. 2007 年中国青 年网络年会报告. 北京.

Gao, E., Tu, X., \& Lou, C. (2003). Reproductive health of unmarried youth in China. Reproduction \& Contraception, 21-31.

Gaventa, J. (2005). Reflections of the uses of the "power cube" approach for analyzing the spaces, places and dynamics of civil society participation and engagement, CFP evaluation series No. 4.

Gaventa, J. (2006). Finding the spaces for change: A power analysis. IDS Bulletin, 37, 1-33. doi:10.1111/j.1759-5436.2006.tb00320.x

Green, A., Gerein, N., Mirzoev, T., Bird, P., Pearson, S., Anh, L. V. et al. (2011). Health policy processes in maternal health: A comparison of Vietnam, India and China. Health Policy, 100, 167-173. doi:10.1016/j.healthpol.2010.11.016

Ha, B. T. T., Green, A., Gerein, N., \& Katrine, D. (2010). Health policy processes in Vietnam: A comparison of three maternal health case studies. Health Policy, 98, 178-185. doi:10.1016/j.healthpol.2010.06.015

HEPVIC Consortium (2007). Revised unified research methodology. Leeds: University of Leeds.

$\mathrm{Hu}, \mathrm{X} ., \mathrm{Xu}, \mathrm{J} ., \mathrm{C}$ Cen, S. (2005). Evaluation report, adolescent reproductive health component of the project CPR/03/P01 "Reproductive Health/Family Planning”. Shanghai: Shanghai Institute of Family Planning Technical Instruction.

$\mathrm{Lu}, \mathrm{Y}$. (2005). The growth of civil society in China key challenges for NGOs. Asia Program, ASP BP 05/01. London: Chatham House.

Zhongguo guojia tongjiju 中国国家统计局 (2010) 2008 nian an nianling he xingbie fenlei renkou 2008 年按年龄和性别分类人口. http://www.stats.gov.cn/tjsj/ndsj/2009/indexch.htm

Guojia renkou yu jihua shengyu weiyuanhui 国家人口与计划生育委 员会 (2003). Guoji renkou fazhan dahui yilai de jinzhan 国际人口 发展大会以来的进展.

Ritchie, J., \& Spencer, L. (1993). Qualitative data analysis for applied policy research. In: A. Bryman, \& R. Burgess (Eds.), Analyzing qualitative data (pp. 173-194). London: Routledge.

Saich, T. (2000). Negotiating the state: The development of social organizations in China. The China Quarterly, 161, 124-141. doi:10.1017/S0305741000003969

Sutcliffe, S., \& Court, J. (2006). A toolkit for progressive policymakers in developing countries. London: Overseas Development Institute.

The government of China \& UNFPA (2006). UNFPA country program action plan 2006-2010. Beijing: The Government of China and UNFPA.

Wang, M., \& Liu, Q. (2009). Analyzing China's NGO development system. The China Nonprofit Review, 1, 5-35. doi:10.1163/187651409X412705

Wang, B., Hertog, S., Meier, A., Lou, C., \& Gao, E. (2005). The potential of comprehensive sex education in China: Findings from suburban Shanghai. International Family Planning Perspectives, 31, 6372. doi:10.1363/3106305

Wang, T. (2010). China's administrative reforms in the economic transition. Asian review of public administration (pp. 256-262). United Nations Public Administration Network.

Zhang, L., Li, X., \& Shah, I. H. (2007). Where do Chinese adolescents obtain knowledge of sex? Implications for sex education in China. Health Education, 107, 351-363. doi:10.1108/09654280710759269 